\title{
Existence and Exponential Stability of Periodic Solution for a Class of Generalized Neural Networks with Arbitrary Delays
}

\author{
Yimin Zhang, ${ }^{1}$ Yongkun $\mathrm{Li}^{2}{ }^{2}$ and Kuohui $\mathrm{Ye}^{2}$ \\ ${ }^{1}$ Department of Mathematics, Zhaotong Teacher's College, Zhaotong, \\ Yunnan 657000, China \\ 2 Department of Mathematics, Yunnan University, Kunming, \\ Yunnan 650091, China \\ Correspondence should be addressed to Yongkun Li, yklie@ynu.edu.cn
}

Received 4 August 2009; Accepted 1 December 2009

Recommended by Jean Mawhin

By the continuation theorem of coincidence degree and $M$-matrix theory, we obtain some sufficient conditions for the existence and exponential stability of periodic solutions for a class of generalized neural networks with arbitrary delays, which are milder and less restrictive than those of previous known criteria. Moreover our results generalize and improve many existing ones.

Copyright (c) 2009 Yimin Zhang et al. This is an open access article distributed under the Creative Commons Attribution License, which permits unrestricted use, distribution, and reproduction in any medium, provided the original work is properly cited.

\section{Introduction}

Consider the following generalized neural networks with arbitrary delays:

$$
x^{\prime}(t)=A(t, x(t))\left[B(t, x(t))+F\left(t, x_{t}\right)\right]
$$

where $A(t, x(t))=\operatorname{diag}\left(a_{1}\left(t, x_{1}(t)\right), a_{2}\left(t, x_{2}(t)\right), \ldots, a_{n}\left(t, x_{n}(t)\right), B(t, x(t))=b_{1}\left(t, x_{1}(t)\right)\right.$, $\left.b_{2}\left(t, x_{2}(t)\right), \ldots, b_{n}\left(t, x_{n}(t)\right)\right)^{T}, F\left(t, x_{t}\right)=\left(f_{1}\left(t, x_{t}\right), f_{2}\left(t, x_{t}\right), \ldots, f_{n}\left(t, x_{t}\right)\right)^{T}, f_{i}\left(t, x_{t}\right)=f_{i}\left(t, x_{1 t}\right.$, $\left.x_{2 t}, \ldots, x_{n t}\right), x_{t}=\left(x_{1 t}, x_{2 t}, \ldots, x_{n t}\right)^{T}$ is defined by $x_{t}(\theta)=x(t+\theta)=\left(x_{1}(t+\theta), x_{2}(t+\theta)\right.$, $\left.\ldots, x_{n}(t+\theta)\right)^{T}, \theta \in E$, and $E$ is a subset of $R^{-}=(-\infty, 0]$.

System (1.1) contains many neural networks, for examples, the higher-order CohenGrossberg type neural networks with delays (see [1]) 


$$
\begin{array}{r}
x_{i}^{\prime}(t)=-a_{i}\left(x_{i}(t)\right)\left[b_{i}\left(x_{i}(t)\right)-\sum_{j=1}^{n} a_{i j}(t) g_{j}\left(x_{j}(t)\right)-\sum_{j=1}^{n} b_{i j}(t) g_{j}\left(x_{j}\left(t-\tau_{j}(t)\right)\right)\right. \\
\left.-\sum_{j=1}^{n} \sum_{l=1}^{n} b_{i j l}(t) g_{j}\left(x_{j}\left(t-\tau_{j}(t)\right)\right) g_{l}\left(x_{l}\left(t-\tau_{l}(t)\right)\right)+I_{i}(t)\right] \\
i=1,2, \ldots, n,
\end{array}
$$

the Cohen-Grossberg neural networks with bounded and unbounded delays (see [2])

$$
\begin{aligned}
x_{i}^{\prime}(t)=-a_{i}\left(t, x_{i}(t)\right)[ & b_{i}\left(t, x_{i}(t)\right)-\sum_{j=1}^{n} c_{i j}(t) f_{j}\left(x_{j}\left(t-\tau_{i j}(t)\right)\right) \\
& \left.-\sum_{j=1}^{n} d_{i j}(t) g_{j}\left(\int_{0}^{\infty} K_{i j}(u) x_{j}(t-u) \mathrm{d} u\right)+I_{i}(t)\right], \quad i=1,2, \ldots, n,
\end{aligned}
$$

the Cohen-Grossberg neural networks with time-varying delays (see [3])

$$
\begin{aligned}
x_{i}^{\prime}(t)=-a_{i}\left(t, x_{i}(t)\right)[ & b_{i}\left(t, x_{i}(t)\right)-\sum_{j=1}^{n} c_{i j}(t) f_{j}\left(x_{j}(t)\right) \\
& \left.-\sum_{j=1}^{n} d_{i j}(t) f_{j}\left(x_{j}\left(t-\tau_{i j}(t)\right)\right)+I_{i}(t)\right], \quad i=1,2, \ldots, n,
\end{aligned}
$$

the celluar neural networks (see [4, Page 193]):

$$
\begin{aligned}
x_{i}^{\prime}(t)= & -r_{i}(t) x_{i}(t)+\sum_{j=1}^{n} a_{i j}(t) g_{j}\left(x_{j}(t)\right) \\
& +\sum_{j=1}^{n} b_{i j}(t) g_{j}\left(x_{j}\left(t-\tau_{i j}(t)\right)\right)+I_{i}(t), \quad i=1,2, \ldots, n,
\end{aligned}
$$

and so on.

Since the model of Cohen-Grossberg neural networks was first introduced by Cohen and Grossberg in [5], the dynamical characteristics (including stable, unstable, and periodic oscillatory) of Cohen-Grossberg neural networks have been widely investigated for the sake of theoretical interest as well as application considerations. Many good results have already been obtained by some authors in [6-15] and the references cited therein. Moreover, the existing results are based on the assumption that demanding either the activation functions, the behaved functions, or delays is bounded in the above-mentioned literature. However, to the best of our knowledge, few authors have discussed the existence and exponential stability of periodic solutions of (1.1). In this paper, by using the continuation theorem of coincidence 
degree and M-matrix theory, we study model (1.1), and get some sufficient conditions for the existence and exponential stability of the periodic solution of system (1.1); our results generalize and improve many existing ones.

Let $A=\left(a_{i j}\right)_{n \times n^{\prime}}, B=\left(b_{i j}\right)_{n \times n} \in R^{n \times n}$ be two matrices, $u=\left(u_{1}, u_{2}, \ldots, u_{n}\right)^{T} \in R^{n}, v=$ $\left(v_{1}, v_{2}, \ldots, v_{n}\right)^{T} \in R^{n}$ be two vectors. For convenience, we introduce the following notations.

(i) $A \geq 0(A>0)$ means that each element $a_{i j}$ is nonnegative (positive) respectively,

(ii) $A \geq B(>B)$ means $A-B \geq 0(>0)$,

(iii) $u \geq 0(u>0)$ means each element $u_{i} \geq 0\left(u_{i}>0\right)$,

(iv) $u \leq v(u<v)$ means $v-u \geq 0 \quad(v-u>0)$,

(v) $|u|=\left(\left|u_{1}\right|,\left|u_{2}\right|, \ldots,\left|u_{n}\right|\right)^{T}$.

For continuous $\omega$-periodic function $g: R \rightarrow R$, we denote $\overline{|g|}=\max _{0 \leq t \leq \omega}|g(t)|, C_{E}=$ $C\left[E, R^{n}\right]$ is the family of continuous functions $\phi=\left(\phi_{1}, \phi_{2}, \ldots, \phi_{n}\right)^{T}$ from $E \subset(-\infty, 0]$ to $R^{n}$. Clearly, it is a Banach space with the norm $\|\phi\|=\max _{0 \leq i \leq n}\left|\phi_{i}\right|$, where $\left|\phi_{i}\right|=\sup _{\theta \in E}\left|\phi_{i}(\theta)\right|$. The initial conditions of system (1.1) are of the form

$$
x_{0}=\phi, \quad \text { that is, } x_{i}(\theta)=\phi_{i}(\theta), \theta \in E, i=1,2, \ldots, n \text {, }
$$

where $\phi=\left(\phi_{1}, \phi_{2}, \ldots, \phi_{n}\right)^{T} \in C_{E}$. For $V(t) \in C((a,+\infty), R)$, let

$$
D^{-} V(t)=\lim \sup _{h \rightarrow 0^{-}} \frac{D(t+h)-D(t)}{h}, \quad D^{-} V(t)=\lim \inf _{h \rightarrow 0^{-}} \frac{D(t+h)-D(t)}{h}, \quad t \in(a,+\infty) .
$$

Throughout this paper, we assume the following:

$\left(H_{1}\right)$ For $i=1,2, \ldots, n, a_{i}, b_{i} \in C\left[R^{2}, R\right], f_{i} \in C\left[R \times C_{E}, R\right]$ and are $\omega$-periodic for their first arguments, respectively, that is, $a_{i}(t+\omega, u)=a_{i}(t, u), b_{i}(t+\omega, u)=b_{i}(t, u), f_{i}(t+$ $\omega, \phi)=f_{i}(t, \phi)$ so $A(t+\omega, u)=A(t, u), B(t+\omega, u)=B(t, u), F(t+\omega, \phi)=F(t, \phi)$, for all $t \in R, u \in R^{n}, \phi \in C_{E}$.

$\left(H_{2}\right)$ There exists a positive diagonal matrix $A=\operatorname{diag}\left(a_{1}, a_{2}, \ldots, a_{n}\right)$ such that $A(t, u) \geq$ $A$, for all $(t, u) \in R^{n+1}$.

$\left(H_{3}\right)$ There is a positive diagonal matrix $B=\operatorname{diag}\left(b_{1}, b_{2}, \ldots, b_{n}\right)$ such that $|B(t, u)| \geq B|u|$, and $b_{i}\left(t, u_{i}\right) u_{i}>0$ or $b_{i}\left(t, u_{i}\right) u_{i}<0$ for all $(t, u) \in R^{n+1}, i=1,2, \ldots, n$.

$\left(H_{4}\right)$ There exist a nonnegative matrix $C=\left(c_{i j}\right)_{n \times n} \in R^{n \times n}$ and a nonnegative vector $D=\left(D_{1}, D_{2}, \ldots, D_{n}\right)^{T}$ such that $|F(t, \phi)| \leq C|\phi|+D$, for all $(t, \phi) \in R \times C_{E}$, where $\phi=\left(\phi_{1}, \phi_{2}, \ldots, \phi_{n}\right)^{T} \in C_{E},|\phi|=\left(\left|\phi_{1}\right|,\left|\phi_{2}\right|, \ldots,\left|\phi_{n}\right|\right)^{T}$.

\section{Preliminaries}

In this section, we first introduce some definitions and lemmas which play an important role in the proof of our main results in this paper. 
Definition 2.1. Let $\tilde{x}(t)=\left(\tilde{x}_{1}(t), \tilde{x}_{2}(t), \ldots, \tilde{x}_{n}(t)\right)^{T}$ be an $\omega$-periodic solution of system (1.1) with initial value $\tilde{\phi} \in C_{E}$, if there exist two constants $\alpha>0$ and $M>1$ such that for every solution $x(t)=\left(x_{1}(t), x_{2}(t), \ldots, x_{n}\right)^{T}$ of system (1.1) with initial value (1.6),

$$
\left|x_{i}(t)-\tilde{x}_{i}(t)\right| \leq M\|\phi-\tilde{\phi}\| e^{-\alpha t}, \quad \forall t>0, i=1,2, \ldots, n
$$

Then $\tilde{x}(t)$ is said to be globally exponential stable.

Definition 2.2. A real matrix $W=\left(w_{i j}\right)_{n \times n} \in R^{n \times n}$ is said to be an $M$-matrix if $w_{i j} \leq 0, i, j=$ $1,2, \ldots, n, i \neq j$, and $W^{-1} \geq 0$.

Lemma 2.3 (see $[15,16]$ ). Assume that $A$ is an M-matrix and $A u \leq d, u, d \in R^{n}$, then $u \leq A^{-1} d$.

Lemma 2.4 (see $[15,16]$ ). Let $W=\left(w_{i j}\right)_{n \times n}$ with $w_{i j} \leq 0, i, j=1,2, \ldots, n, i \neq j$, then the following statements are equivalent.

(i) $W$ is an M-matrix.

(ii) There exists a positive vector $\eta=\left(\eta_{1}, \eta_{2}, \ldots, \eta_{n}\right)>0$ such that $\eta W>0$.

(iii) There exists a positive vector $\xi=\left(\xi_{1}, \xi_{2}, \ldots, \xi_{n}\right)^{T}>0$ such that $W \xi>0$.

Lemma 2.5 (see $[15,16])$. Let $A \geq 0$ be an $n \times n$ matrix and $\rho(A)<1$, then $\left(E_{n}-A\right)^{-1} \geq 0$, where $E_{n}$ denotes the identity matrix of size $n$, so $E_{n}-A$ is an M-matrix.

Now we introduce Mawhin's continuation theorem which will be fundamental in this paper.

Lemma 2.6 (see [17]). Let $X$ and $Y$ be two Banach spaces and L a Fredholm mapping of index zero. Assume that $\Omega \subset X$ is an open bounded set and $N: X \rightarrow Z$ is a continuous operator which is $L$-compact on $\bar{\Omega}$. Then $L x=N x$ has at least one solution in $\operatorname{Dom} L \cap \bar{\Omega}$, if the following conditions are satisfied:

(1) $L x \neq \lambda N x$, for all $(x, \lambda) \in(\operatorname{Dom} L \cap \partial \Omega) \times(0,1)$,

(2) $Q N x \neq 0$, for all $x \in \partial \Omega \cap \operatorname{Ker} L$,

(3) $\operatorname{deg}\left\{\left.J Q N\right|_{\operatorname{Ker} L \cap \bar{\Omega}}, \Omega \cap \operatorname{Ker} L, 0\right\} \neq 0$.

Let

$$
X=Y=\left\{x=\left(x_{1}, x_{2}, \ldots, x_{n}\right)^{T} \in C\left(R, R^{n}\right): x(t+\omega)=x(t), t \in R\right\}
$$

with the norm defined by $\|x\|=\max _{1 \leq i \leq n} \overline{\left|x_{i}\right|}$, where $\overline{\left|x_{i}\right|}=\max _{t \in[0, \omega]}\left|x_{i}(t)\right|$. Clearly, $X$ and $Y$ are two Banach spaces. Let $x=\left(x_{1}, x_{2}, \ldots, x_{n}\right)^{T} \in X=Y$, we define the linear operator $L:$ Dom $L \subset X \rightarrow Y$ as

$$
(L x)(t)=x^{\prime}(t)=\left(x_{1}^{\prime}(t), x_{2}^{\prime}(t), \ldots, x_{n}^{\prime}(t)\right)^{T}, \quad \operatorname{Dom} L=\left\{x \in X: x^{\prime} \in Y\right\},
$$


and the operators $N: X \rightarrow X, P: X \rightarrow X, Q: Y \rightarrow Y$ as

$$
\begin{aligned}
(N x)(t) & =A(t, x(t))\left[B(t, x(t))+F\left(t, x_{t}\right)\right]:=\Delta\left(t, x_{t}\right), \\
P x & =Q x=\frac{1}{\omega} \int_{0}^{\omega} x(t) \mathrm{d} t \\
& =\left(\frac{1}{\omega} \int_{0}^{\omega} x_{1}(t) \mathrm{d} t, \frac{1}{\omega} \int_{0}^{\omega} x_{2}(t) \mathrm{d} t, \ldots, \frac{1}{\omega} \int_{0}^{\omega} x_{n}(t) \mathrm{d} t\right)^{T} .
\end{aligned}
$$

It is not difficult to show that $P$ and $Q$ are continuous projectors and the following conditions are satisfied:

Ker $L=R^{n}=\operatorname{Im} P=\operatorname{Im} Q$,

$$
\operatorname{Im} L=\left\{y \in Y=X: \int_{0}^{\omega} y(t) \mathrm{d} t=0\right\}=\operatorname{Ker} Q=\operatorname{Im}(I-Q),
$$

$\operatorname{Im} L$ is closed in $Y, \operatorname{dim} \operatorname{Ker} L=n=\operatorname{codim} \operatorname{Im} L$.

Thus, the mapping $L$ is a Fredholm mapping of index zero and the isomorphism $J: \operatorname{Im} Q \rightarrow$

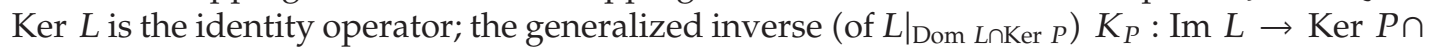
Dom $L$ exists, which has the form

$$
\left(K_{P} x\right)(t)=\int_{0}^{t} x(s) \mathrm{d} s-\frac{1}{\omega} \int_{0}^{\omega} \int_{0}^{t} x(s) \mathrm{d} s \mathrm{~d} t, \quad \forall x \in \operatorname{Im} L .
$$

Therefore

$$
\begin{gathered}
(Q N x)(t)=\frac{1}{\omega} \int_{0}^{\omega} \Delta\left(t, x_{t}\right) \mathrm{d} t \\
\left(K_{P}(I-Q) N x\right)(t)=\int_{0}^{t} \Delta\left(s, x_{s}\right) \mathrm{d} s-\frac{1}{\omega} \int_{0}^{\omega} \int_{0}^{t} \Delta\left(s, x_{s}\right) \mathrm{d} s \mathrm{~d} t+\left(\frac{1}{2}-\frac{t}{\omega}\right) \int_{0}^{\omega} \Delta\left(s, x_{s}\right) \mathrm{d} s .
\end{gathered}
$$

\section{Existence of Periodic Solutions}

In this section, we shall use Lemma 2.6 to study the existence of at least one periodic solution of system (1.1).

Theorem 3.1. Let $\left(H_{1}\right)-\left(H_{4}\right)$ hold. Moveover, suppose that

$\left(H_{5}\right) E-K$ is a M-matrix, where the matrix $K=\left(k_{i j}\right)_{n \times n}=B^{-1} C$.

then

(i) system (1.1) has at least one w-periodic solution;

(ii) there exists a nonnegative constant $\delta$ such that for all w-periodic solution $x(t)=$ $\left(x_{1}(t), x_{2}(t), \ldots, x_{n}(t)\right)^{T}$ of system $(1.1),\left|x_{i}(t)\right| \leq \delta, i=1,2, \ldots, n$. 
Proof. Clearly, $Q N$ and $K_{P}(I-Q) N$ are continuous functions and for every bounded subset $\Omega \subset X, Q N(\bar{\Omega}), K_{P}(I-Q) N(\bar{\Omega})$, and $\left(K_{P}(I-Q) N x\right)^{\prime}, x \in \bar{\Omega}$ are bounded. By using the Arzela-Ascoli theorem, $Q N(\bar{\Omega})$ and $K_{P}(I-Q) N(\bar{\Omega})$ are compact, therefore $N$ is $L$-compact on $\bar{\Omega}$. Consider the following operator equation:

$$
L x=\lambda N x, \quad \lambda \in(0,1)
$$

That is,

$$
x^{\prime}(t)=\lambda A(t, x(t))\left[B(t, x(t))+F\left(t, x_{t}\right)\right]
$$

or

$$
x_{i}^{\prime}(t)=\lambda a_{i}\left(t, x_{i}(t)\right)\left[b_{i}\left(t, x_{i}(t)\right)+f_{i}\left(t, x_{t}\right)\right], \quad i=1,2, \ldots, n .
$$

Assume that $x(t)=\left(x_{1}(t), x_{2}(t), \ldots, x_{n}(t)\right)^{T} \in X$ is a solution of (3.3) for some $\lambda \in(0,1)$. Then, for any $i=1,2, \ldots, n, x_{i}(t)$ are all continuous $\omega$-periodic functions, and there exist $t_{i} \in[0, \omega]$, such that

$$
\left|x_{i}\left(t_{i}\right)\right|=\max _{t \in[0, \omega]}\left|x_{i}(t)\right|=\overline{\left|x_{i}\right|}, \quad x_{i}^{\prime}\left(t_{i}\right)=0, i=1,2, \ldots, n,
$$

from $\left(H_{2}\right)$, we have

$$
b_{i}\left(t_{i}, x_{i}\left(t_{i}\right)\right)+f_{i}\left(t_{i}, x_{t_{i}}\right)=0, \quad i=1,2, \ldots, n
$$

It follows from $\left(\mathrm{H}_{3}\right)$ that

$$
\begin{aligned}
b_{i} \overline{\left|x_{i}\right|} & \leq\left|b_{i}\left(t_{i}, x_{i}\left(t_{i}\right)\right)\right|=\left|f_{i}\left(t_{i}, x_{t_{i}}\right)\right| \\
& \leq \sum_{j=1}^{n} c_{i j}\left|x_{j t_{i}}\right|+D_{i} \leq \sum_{j=1}^{n} c_{i j} \overline{\left|x_{j}\right|}+D_{i}, \quad i=1,2, \ldots, n .
\end{aligned}
$$

Thus

$$
\overline{\left|x_{i}\right|} \leq b_{i}^{-1} \sum_{j=1}^{n} c_{i j} \overline{\left|x_{j}\right|}+b_{i}^{-1} D_{i}, \quad i=1,2, \ldots, n
$$

we denote the vector $d=\left(d_{1}, d_{2}, \ldots, d_{n}\right)^{T}, \overline{|x|}=\left(\overline{\left|x_{1}\right|}, \overline{\left|x_{2}\right|}, \ldots, \overline{\left|x_{n}\right|}\right)^{T}$, where $d_{i}=b_{i}^{-1}\left(D_{i}+1\right)>$ $0, i=1,2, \ldots, n$. It follows from (3.7) that

$$
(E-K) \overline{|x|}<d .
$$


Since $\left(H_{5}\right)$, and application of Lemma 2.3 yields

$$
\overline{|x|}<(E-K)^{-1} d=\left(h_{1}, h_{2}, \ldots, h_{n}\right)^{T}=h,
$$

where $h$ satisfies the equation $h=K h+d$, that is, $h_{i}=\sum_{j=1}^{n} k_{i j} h_{j}+d_{i}>0$.

Take

$$
\Omega=\left\{x \in X: \overline{\left|x_{i}\right|}<h_{i}, i=1,2, \ldots, n\right\} .
$$

It is easy to see that $\Omega$ satisfies condition (1) in Lemma 2.6.

For all $x=\left(x_{1}, x_{2}, \ldots, x_{n}\right)^{T} \in \partial \Omega \cap \operatorname{Ker} L, x$ is a constant vector in $R^{n}$ and there exists some $i \in\{1,2, \ldots, n\}$ such that $\left|x_{i}\right|=\overline{\left|x_{i}\right|}=h_{i}$, we claim that

$$
\left|(Q N x)_{i}\right|>0, \quad \text { so that } Q N x \neq 0 .
$$

We firstly claim that

(1) if $b_{i}\left(t, u_{i}\right) u_{i}>0$, then $x_{i}(Q N x)_{i}>0$,

(2) if $b_{i}\left(t, u_{i}\right) u_{i}<0$, then $x_{i}(Q N x)_{i}<0$.

We only prove (1), since the proof of (2) is similar. If $b_{i}\left(t, u_{i}\right) u_{i}>0$, we have

$$
\begin{aligned}
x_{i}\left[b_{i}\left(t, x_{i}(t)\right)+f_{i}\left(t, x_{t}\right)\right] & \geq b_{i} x_{i}^{2}-\left|x_{i}\right|\left[\sum_{j=1}^{n} c_{i j} \overline{\left|x_{j}\right|}+D_{i}\right] \\
& >b_{i} h_{i}\left[h_{i}-\left(\sum_{j=1}^{n} b_{i}^{-1} c_{i j} h_{j}+d_{i}\right)\right] \\
& =b_{i} h_{i}\left[h_{i}-\left(\sum_{j=1}^{n} k_{i j} h_{j}+d_{i}\right)\right]=0 .
\end{aligned}
$$

Therefore

$$
x_{i}(Q N x)_{i}=\omega^{-1} x_{i} \int_{0}^{\omega} a_{i}\left(t, x_{i}(t)\right)\left[b_{i}\left(t, x_{i}(t)\right)+f_{i}\left(t, x_{t}\right)\right] \mathrm{d} t>0
$$

Thus (3.11) is valid.

Next, we define continuous functions $H_{i}:(\Omega \cap \operatorname{Ker} L) \times[0,1] \rightarrow \Omega \cap \operatorname{Ker} L, i=1,2$, by

$$
\begin{aligned}
& H_{1}(x, t)=t x+(1-t) Q N x, \quad \forall(x, t) \in(\Omega \cap \operatorname{Ker} L) \times[0,1] \\
& H_{2}(x, t)=-t x+(1-t) Q N x, \quad \forall(x, t) \in(\Omega \cap \operatorname{Ker} L) \times[0,1]
\end{aligned}
$$


respectively. If $b_{i}\left(t, u_{i}\right) u_{i}>0$, from (i) we have

$$
H_{1}(x, t) \neq 0, \quad \forall(x, t) \in \operatorname{Ker} L \bigcap \partial \Omega \times[0,1],
$$

If $b_{i}\left(t, u_{i}\right) u_{i}<0$, from (2) we can get

$$
H_{2}(x, t) \neq 0, \quad \forall(x, t) \in \operatorname{Ker} L \bigcap \partial \Omega \times[0,1] .
$$

Using the homotopy invariance theorem, we obtain if $b_{i}\left(t, u_{i}\right) u_{i}>0$,

$$
\begin{aligned}
\operatorname{deg}\left\{\left.J Q N\right|_{\bar{\Omega} \cap \operatorname{Ker} L}, \Omega \cap \operatorname{Ker} L, 0\right\} & =\operatorname{deg}\left\{H_{1}(\cdot, 0), \Omega \cap \operatorname{Ker} L, 0\right\} \\
& =\operatorname{deg}\left\{H_{1}(\cdot, 1), \Omega \cap \operatorname{Ker} L, 0\right\} \\
& =\operatorname{deg}\{x, \Omega \cap \operatorname{Ker} L, 0\}=1,
\end{aligned}
$$

or if $b_{i}\left(t, u_{i}\right) u_{i}<0$,

$$
\begin{aligned}
\operatorname{deg}\left\{\left.J Q N\right|_{\bar{\Omega} \cap \operatorname{Ker} L}, \Omega \cap \operatorname{Ker} L, 0\right\} & =\operatorname{deg}\left\{H_{2}(\cdot, 0), \Omega \cap \operatorname{Ker} L, 0\right\} \\
& =\operatorname{deg}\left\{H_{2}(\cdot, 1), \Omega \cap \operatorname{Ker} L, 0\right\} \\
& =\operatorname{deg}\{-x, \Omega \cap \operatorname{Ker} L, 0\}=(-1)^{n} .
\end{aligned}
$$

To summarize, $\Omega$ satisfies all the conditions of Lemma 2.6. This completes the proof of (i).

For all $\omega$-periodic solution $x(t)=\left(x_{1}(t), x_{2}(t), \ldots, x_{n}(t)\right)^{T}$ of system (1.1), from (3.3)(3.7) we have

$$
\begin{gathered}
\overline{\left|x_{i}\right|} \leq b_{i}^{-1} \sum_{j=1}^{n} c_{i j} \overline{\left|x_{j}\right|}+b_{i}^{-1} D_{i}, \\
\overline{|x|} \leq(E-K)^{-1} v=v=\left(v_{1}, v_{2}, \ldots, v_{n}\right)^{T},
\end{gathered}
$$

where $v=\left(v_{1}, v_{2}, \ldots, v_{n}\right)^{T}, \overline{|x|}=\left(\overline{\left|x_{1}\right|}, \overline{\left|x_{2}\right|}, \ldots, \overline{\left|x_{n}\right|}\right)^{T}, v_{i}=b_{i}^{-1} D_{i} \geq 0, i=1,2, \ldots, n$. Notes $\delta=\max _{1 \leq i \leq n} v_{i} \geq 0$, thus $\left|x_{i}(t)\right| \leq \delta$, for all $i=1,2, \ldots, n$. This completes the proof of (ii).

From the proof of Theorem 3.1, we can easily obtain the following corollary.

Corollary 3.2. Suppose that $\left(H_{1}\right)-\left(H_{5}\right)$ hold, and $D=0$ in $\left(H_{4}\right)$, then system (1.1) has only one w-periodic solution $x(t)=0$.

Some special cases of Theorem 3.1 are in what follows.

Corollary 3.3. Equation (1.3) has at least one w-periodic solution, if the following conditions are satisfied.

$\left(A_{1}\right)$ For $i, j=1,2, \ldots, n, a_{i}, b_{i}, a_{i j}, b_{i j}, \tau_{j}, I_{i}: R \rightarrow R$ are continuous $\omega$-periodic $(\omega>0)$ functions. 
Abstract and Applied Analysis

$\left(A_{2}\right)$ For $i=1,2, \ldots, n, a_{i}(x)$ are positive, and there exist $a_{i}>0$ such that $a_{i}(x) \geq a_{i}>0$.

$\left(A_{3}\right)$ For $i=1,2, \ldots, n$, there exist $b_{i}>0$ such that

$$
\left|b_{i}(x)\right| \geq b_{i}|x|, \quad b_{i}(x) x>0, \quad \text { or } \quad b_{i}(x) x<0, \quad \forall x \in R
$$

$\left(A_{4}\right)$ For $i=1,2, \ldots, n$, there exist $G_{i}, p_{i}, q_{i} \geq 0$ such that

$$
\left|g_{i}(x)\right| \leq G_{i}, \quad\left|g_{i}(x)\right| \leq p_{i}|x|+q_{i}
$$

$\left(A_{5}\right) \rho(K)<1, K=\left(k_{i j}\right)_{n \times n^{\prime}}$ and $k_{i j}=b_{i}^{-1}\left(\overline{\left|a_{i j}\right|}+\overline{\left|b_{i j}\right|}+\sum_{j=1}^{n} \overline{\left|b_{i j l}\right|} G_{l}\right) p_{j}, i, j=1,2, \ldots, n$.

Proof. It is clear that

$$
\begin{aligned}
A(t, x)= & \operatorname{diag}\left(a_{1}\left(x_{1}\right), a_{2}\left(x_{2}\right), \ldots, a_{n}\left(x_{n}\right)\right) \\
\geq & \operatorname{diag}\left(a_{1}, a_{2}, \ldots, a_{n}\right)=A, \\
|B(t, x)|= & \left(\left|b_{1}\left(x_{1}\right)\right|,\left|b_{2}\left(x_{2}\right)\right|, \ldots,\left|b_{n}\left(x_{n}\right)\right|\right)^{T} \\
\geq & \left(b_{1}\left|x_{1}\right|, b_{2}\left|x_{2}\right|, \ldots, b_{n}\left|x_{n}\right|\right)^{T} \\
= & \operatorname{diag}\left(b_{1}, b_{2}, \ldots, b_{n}\right)\left(\left|x_{1}\right|,\left|x_{2}\right|, \ldots,\left|x_{n}\right|\right)^{T}=B|x|, \\
\left|f_{i}(t, \phi)\right|= & \mid \sum_{j=1}^{n} a_{i j}(t) g_{j}\left(\phi_{j}(0)\right)+\sum_{j=1}^{n} b_{i j}(t) g_{j}\left(\phi_{j}\left(-\tau_{j}(t)\right)\right) \\
& +\sum_{j=1}^{n} \sum_{l=1}^{n} b_{i j l}(t) g_{j}\left(\phi_{j}\left(-\tau_{j}(t)\right)\right) g_{l}\left(\phi_{l}\left(-\tau_{l}(t)\right)\right)-I_{i}(t) \mid \\
\leq & \sum_{j=1}^{n} \overline{\left|a_{i j}\right|}\left[p_{j}\left|\phi_{j}\right|+q_{j}\right]+\sum_{j=1}^{n} \overline{\left|b_{i j}\right|}\left[p_{j}\left|\phi_{j}\right|+q_{j}\right] \\
& +\sum_{j=1}^{n} \sum_{l=1}^{n} G_{l} \overline{\left|b_{i j l}\right|}\left(p_{j}\left|\phi_{j}\right|+q_{j}\right)+\overline{\left|I_{i}\right|} \\
& +\sum_{j=1}^{n}\left[\overline{\left|a_{i j}\right|}+\overline{\left|b_{i j}\right|}+\sum_{l=1}^{n} \overline{\left|b_{i j l}\right|} G_{l}\right] q_{j}+\overline{\left|I_{i}\right|}=\sum_{j=1}^{n} c_{i j}\left|\phi_{j}\right|+D_{i}, \quad i=1,2, \ldots, n . \\
= & \sum_{j=1}^{n}\left[\overline{\left|a_{i j}\right|}+\overline{\left|b_{i j}\right|}+\sum_{l=1}^{n} \overline{\left|b_{i j l}\right|} G_{l}\right] p_{j}\left|\phi_{j}\right| \\
&
\end{aligned}
$$

Thus

$$
|f(t, \phi)| \leq C|\phi|+D,
$$


where $C=\left(c_{i j}\right)_{n \times n} \in R^{n \times n}, D=\left(D_{1}, D_{2}, \ldots, D_{n}\right)^{T}, c_{i j}=\left[\overline{\left|a_{i j}\right|}+\overline{\left|b_{i j}\right|}+\sum_{l=1}^{n} \overline{\left|b_{i j l}\right|} G_{l}\right] p_{j} \geq 0, D_{i}=$ $\sum_{j=1}^{n}\left[\overline{\left|a_{i j}\right|}+\overline{\left|b_{i j}\right|}+\sum_{l=1}^{n} \overline{\left|b_{i j}\right|} G_{l}\right] q_{j}+\overline{\left|I_{i}\right|} \geq 0, i, j=1,2, \ldots, n$. Therefore, by using Lemma 2.5 and Theorem 3.1, we know that (1.3) has an $\omega$-periodic solution. The proof is complete.

Remark 3.4. For [1, Equation (1.2)], $\tau_{j}(t), j=1,2, \ldots, n$ are continuous differentiable $\omega$ periodic solutions and $0 \leq \tau_{j}^{\prime}(t) \leq 1$, this implies that $\tau_{j}(t), j=1,2, \ldots, n$ are constant functions, thus $\xi_{j}=1, j=1,2, \ldots, n$. It is not difficult to verify that all of conditions of Corollary 3.3 are satisfied under the conditions of [1, Theorem 1] moreover the other requirements of [1, Theorem 1] are more restrictive than ours. Therefore, Corollary 3.3 improves the corresponding result obtained in [1].

Corollary 3.5. If the following conditions are satisfied:

$\left(B_{1}\right)$ for $i, j=1,2, \ldots, n, c_{i j}, d_{i j}, \tau_{i j}, I_{i}: R \rightarrow R$ are continuous $\omega$-periodic $(\omega>0)$ functions, $a_{i}, b_{i}$ are continuous functions on $R^{2}$, and are $\omega$-periodic for their first arguments, respectively,

$\left(B_{2}\right)$ for $i=1,2, \ldots, n$, there exist positive constants $a_{i}$ such that $a_{i}(t, u) \geq a_{i}$, for all $t, u \in R$,

$\left(B_{3}\right)$ for $i=1,2, \ldots, n$, there exist positive constants $b_{i}$ such that $\left|b_{i}(t, u)\right| \geq b_{i}|u|, b_{i}(u) u>$ 0 or $b_{i}(u) u<0$, for all $t, u \in R$,

$\left(B_{4}\right)$ there exist nonnegative constants $p_{j}^{f}, q_{j}^{f}, p_{j}^{g}, q_{j}^{g}$ such that

$$
\left|f_{j}(u)\right| \leq p_{j}^{f}|u|+q_{j}^{f}, \quad\left|g_{j}(u)\right| \leq p_{j}^{g}|u|+q_{j}^{g}, \quad \forall u \in R, j=1,2, \ldots, n,
$$

$\left(B_{5}\right)$ the delay kernels $K_{i j}:[0, \infty] \rightarrow R$ satisfy

$$
\int_{0}^{\infty}\left|K_{i j}(s)\right| d s \leq k_{i j}, \quad i, j=1,2, \ldots, n,
$$

$\left(B_{6}\right) \rho(K)<1, K=\left(k_{i j}\right)_{n \times n} \in R^{n \times n}$, where $k_{i j}=b_{i}^{-1}\left(\overline{\left|c_{i j}\right|} p_{j}^{f}+\overline{\left|d_{i j}\right|} k_{i j} p_{j}^{g}\right), i, j=1,2, \ldots, n$.

then (1.3) has at least one w-periodic solution.

Remark 3.6. In [2, Theorem 3.1], the activation functions $f_{j}(u), g_{j}(u), j=1,2, \ldots, n$, are required to be Lipschitzian, which implies that condition $\left(B_{3}\right)$ in Corollary 3.5 holds. Therefore, Corollary 3.5 improves Theorem 3. In 2.

Corollary 3.7. Assume that the following conditions are satisfied:

$\left(C_{1}\right) c_{i j}, d_{i j}, \tau_{i j}, I_{i}: R \rightarrow R$ are continuous $\omega$-periodic $(\omega>0)$ functions, $a_{i}, b_{i}$ are continuous functions on $R^{2}$, and are $\omega$-periodic in the first variable,

$\left(C_{2}\right)$ there exist positive constants $a_{i}$ such that

$$
a_{i}(t, u) \geq a_{i}, \quad \forall t, u \in R, i=1,2, \ldots, n,
$$


$\left(C_{3}\right)$ there exist positive constants $b_{i}$ such that

$$
\left|b_{i}(t, u)\right| \geq b_{i}|u|, \quad b_{i}(u) u>0 \quad \text { or } \quad b_{i}(u) u<0, \quad \forall t, u \in R, i=1,2, \ldots, n,
$$

$\left(C_{4}\right)$ There exist nonnegative constants $p_{i}, q_{i}$ such that

$$
\left|f_{i}(u)\right| \leq p_{i}|u|+q_{i}, \quad \forall u \in R, i=1,2, \ldots, n,
$$

$\left(C_{5}\right) \rho(K)<1$, where $K=\left(k_{i j}\right)_{n \times n} \in R^{n \times n}$ and $k_{i j}=b_{i}^{-1}\left(\overline{\left|c_{i j}\right|}+\overline{\left|d_{i j}\right|}\right) p_{j}, i, j=1,2, \ldots, n$.

Then (1.4) has at least one $\omega$-periodic solution.

Remark 3.8. In [3, Theorem 3.1], the activation functions $f_{j}(u), j=1,2, \ldots, n$, are Lipschitzian (which also implies that condition $\left(C_{4}\right)$ in Corollary 3.7 holds) and the behaved functions $b_{i}(t, u)$ are required to satisfy that there exist positive constants $\underline{b}_{i}, \bar{b}_{i}$ such that $0 \leq$ $u b_{i}(t, u), \underline{b}_{i}|u| \leq\left|b_{i}(t, u)\right| \leq \bar{b}_{i}|u|$ for all $t, u \in R, i=1,2, \ldots, n$, which are more restrictive than that of Corollary 3.7.

Corollary 3.9. Assume that the following conditions are satisfied

$\left(D_{1}\right)$ For $i, j=1,2, \ldots, n, I_{i}, a_{i j}, b_{i j}, \tau_{i j}: R \rightarrow R$ are continuous $\omega$-periodic solution $(\omega>0)$ functions.

$\left(D_{2}\right)$ For $j=1,2, \ldots, n, g_{j}: R \rightarrow R$ are continuous functions and there exist nonnegative constants $p_{j}, q_{j}$ such that

$$
\left|g_{j}(v)\right| \leq p_{j}|v|+q_{j}, \quad \forall v \in R, j=1,2, \ldots, n,
$$

$\left(D_{3}\right) \rho(K)<1, K=\left(k_{i j}\right)_{n \times n} \in R^{n \times n}$ and $k_{i j}=r_{i}^{-1}\left(\overline{\left|a_{i j}\right|}+\overline{\left|b_{i j}\right|}\right) p_{j}, i, j=1,2, \ldots, n$,

then (1.5) has at least one w-periodic solution.

The proofs of Corollaries 3.5-3.9 are the same as that of Corollary 3.3.

\section{Uniqueness and Exponential Stability of Periodic Solution}

In this section, we establish some results for the uniqueness and exponential stability of the $\omega$-periodic solution of (1.1).

Theorem 4.1. Assume that $E$ is a bounded subset of $R^{-}$, and $\left(H_{1}\right)-\left(H_{3}\right)$ and $\left(H_{5}\right)$ hold. Suppose also the following conditions are satisfied.

$\left(H_{4}\right)^{\prime}$ There exists a nonnegative matrix $C=\left(c_{i j}\right)_{n \times n} \in R^{n \times n}$ such that

$$
|F(t, \phi)-F(t, \varphi)| \leq C|\phi-\varphi|, \quad \forall(t, \phi),(t, \varphi) \in R \times C_{E},
$$

where $\phi=\left(\phi_{1}, \phi_{2}, \ldots, \phi_{n}\right)^{T}, \varphi=\left(\varphi_{1}, \varphi_{2}, \ldots, \varphi_{n}\right)^{T} \in C_{E},|\phi-\varphi|=\left(\left|\phi_{1}-\varphi_{1}\right|,\left|\phi_{2}-\varphi_{2}\right|\right.$, $\left.\ldots,\left|\phi_{n}-\varphi_{n}\right|\right)^{T}$. 
$\left(H_{6}\right) a_{i}, i=1,2, \ldots, n$, are Lipschitzian with Lipschitz constants $L_{i}^{a}>0$, and there exist $\bar{a}_{i}$ such that

$a_{i}(t, u) \leq \bar{a}_{i}, \quad\left|a_{i}(t, u)-a_{i}(t, v)\right| \leq L_{i}^{a}|u-v|, \quad \forall(t, u),(t, v) \in R^{2}, i=1,2, \ldots, n$.

$\left(H_{7}\right)$ For all $t, u, v \in R, i=1,2, \ldots, n$, there exist positive constants $L_{i}^{a b}$ such that

$$
\begin{array}{r}
{\left[a_{i}(t, u) b_{i}(t, u)-a_{i}(t, v) b_{i}(t, v)\right](u-v) \leq 0, \quad i=1,2, \ldots, n,} \\
\left|a_{i}(t, u) b_{i}(t, u)-a_{i}(t, v) b_{i}(t, v)\right| \geq L_{i}^{a b}|u-v|, \quad i=1,2, \ldots, n .
\end{array}
$$

$\left(H_{8}\right)$ For $i=1,2, \ldots, n$, set $\Delta_{i}=\max _{0 \leq t \leq \omega}\left|f_{i}(t, 0)\right|$, and assume that $E_{n}-W$ is an M-matrix, where $W=\left(w_{i j}\right)_{n \times n} \in R^{n \times n}$, and

$$
w_{i j}=\left(L_{i}^{a b}-L_{i}^{a} \Delta_{i}\right)^{-1}\left(\bar{a}_{i}+L_{i}^{a} \delta\right) c_{i j}, \quad L_{i}^{a b}-L_{i}^{a} \Delta_{i}>0, i, j=1,2, \ldots, n
$$

Proof. Obviously, $\left(H_{4}\right)^{\prime}$ implies $\left(H_{4}\right)$, since $\left(H_{1}\right)-\left(H_{5}\right)$ hold, it follows from Theorem 3.1 that system (1.1) has at least one $\omega$-periodic solution

$$
\tilde{x}(t)=\left(\tilde{x}_{1}(t), \tilde{x}_{2}(t), \ldots, \tilde{x}_{n}(t)\right)^{T}
$$

with the initial value $\tilde{\phi}=\left(\tilde{\phi}_{1}, \tilde{\phi}_{2}, \ldots, \tilde{\phi}_{n}\right)^{T} \in C_{E}$. Let

$$
x(t)=\left(x_{1}(t), x_{2}(t), \ldots, x_{n}(t)\right)^{T}
$$

be an arbitrary solution of system (1.1) with the initial value (1.6), set $y(t)=x(t)-\tilde{x}(t)$. Then for $i=1,2, \ldots, n$,

$$
\begin{aligned}
y_{i}^{\prime}(t)= & a_{i}\left(t, y_{i}(t)+\tilde{x}_{i}(t)\right) b_{i}\left(t, y_{i}(t)+\tilde{x}_{i}(t)\right)-a_{i}\left(t, \tilde{x}_{i}(t)\right) b_{i}\left(t, \tilde{x}_{i}(t)\right) \\
& +a_{i}\left(t, y_{i}(t)+\tilde{x}_{i}(t)\right)\left[f_{i}\left(t, y_{t}+\tilde{x}_{t}\right)-f_{i}\left(t, \tilde{x}_{t}\right)\right] \\
& +f_{i}\left(t, \tilde{x}_{t}\right)\left[a_{i}\left(t, x_{i}(t)\right)-a_{i}\left(t, \tilde{x}_{i}(t)\right)\right] .
\end{aligned}
$$

Thus, for $i=1,2, \ldots, n$,

$$
\begin{aligned}
D^{-}\left|y_{i}(t)\right| & \leq-L_{i}^{a b}\left|y_{i}(t)\right|+\bar{a}_{i} \sum_{j=1}^{n} c_{i j}\left|y_{i t}\right|+L_{i}^{a}\left|y_{i}(t)\right|\left[\sum_{j=1}^{n} c_{i j}\left|\tilde{x}_{i t}\right|+\left|f_{i}(t, 0)\right|\right] \\
& \leq-\left(L_{i}^{a b}-L_{i}^{a} \Delta_{i}\right)\left|y_{i}(t)\right|+\left(\bar{a}_{i}+L_{i}^{a} \delta\right) \sum_{j=1}^{n} c_{i j}\left|y_{i t}\right|,
\end{aligned}
$$


for $\left(H_{8}\right)$ and Lemma 2.4, there exist a positive constant $\sigma>0$ and a positive constant vector $\xi=\left(\xi_{1}, \xi_{2}, \ldots, \xi_{n}\right)^{T}>0$ such that $\left(E_{n}-W\right) \xi>(\sigma, \sigma, \ldots, \sigma)^{T}$. Hence

$$
\xi_{i}-\sum_{j=1}^{n} w_{i j} \xi_{j}>\sigma
$$

where $w_{i j}=\left(L_{i}^{a b}-L_{i}^{a} \Delta_{i}\right)^{-1}\left(\bar{a}_{i}+L_{i}^{a} \delta\right) c_{i j}, i, j=1,2, \ldots, n$. Moreover for all $i=1,2, \ldots, n$,

$$
-\left(L_{i}^{a b}-L_{i}^{a} \Delta_{i}\right) \xi_{i}+\left(\bar{a}_{i}+L_{i}^{a} \delta\right) \sum_{j=1}^{n} c_{i j} \xi_{j}<\left(L_{i}^{a b}-L_{i}^{a} \Delta_{i}\right) \sigma
$$

Since, $E$ is a bounded subset of $R^{-}$, we can choose a positive constant $\alpha<1$, such that $\forall \theta \in E$

$$
\alpha \xi_{i}+\left[-\left(L_{i}^{a b}-L_{i}^{a} \Delta_{i}\right) \xi_{i}+\left(\bar{a}_{i}+L_{i}^{a} \delta\right) \sum_{j=1}^{n} c_{i j} \xi_{j} e^{-\alpha \theta}\right]<0, \quad i=1,2, \ldots, n,
$$

and also can choose a positive constant $\beta>1$ such that

$$
\beta \xi_{i} e^{-\alpha \theta}>1, \quad \forall \theta \in E, i=1,2, \ldots, n .
$$

Set, for all $\varepsilon>0$, for all $t \in E$,

$$
Z_{i}(t)=\beta \xi_{i}\left[\sum_{j=1}^{n}\left|y_{j 0}\right|+\varepsilon\right] e^{-\alpha t}, \quad i=1,2, \ldots, n
$$

It follows from (4.11) and (4.13) that

$$
\begin{aligned}
D_{-} Z_{i}(t)= & -\alpha \beta \xi_{i}\left[\sum_{j=1}^{n}\left|y_{j 0}\right|+\varepsilon\right] e^{-\alpha t} \\
& >\left[-\left(L_{i}^{a b}-L_{i}^{a} \Delta_{i}\right) \xi_{i}+\left(\bar{a}_{i}+L_{i}^{a} \delta\right) \sum_{j=1}^{n} c_{i j} \xi_{j} e^{-\alpha \theta}\right] \beta\left[\sum_{j=1}^{n}\left|y_{j 0}\right|+\varepsilon\right] e^{-\alpha t} \\
= & -\left(L_{i}^{a b}-L_{i}^{a} \Delta_{i}\right) \xi_{i} \beta\left[\sum_{j=1}^{n}\left|y_{j 0}\right|+\varepsilon\right] e^{-\alpha t} \\
& +\left(\bar{a}_{i}+L_{i}^{a} \delta\right) \sum_{j=1}^{n} c_{i j} \xi_{j} e^{-\alpha(\theta+t)} \beta\left[\sum_{j=1}^{n}\left|y_{j 0}\right|+\varepsilon\right], \quad \forall \theta \in E .
\end{aligned}
$$


Thus

$$
D \_Z_{i}(t) \geq-\left(L_{i}^{a b}-L_{i}^{a} \Delta_{i}\right) Z_{i}(t)+\left(\bar{a}_{i}+L_{i}^{a} \delta\right) \sum_{j=1}^{n} c_{i j}\left|Z_{j t}\right|
$$

where $\left|Z_{j t}\right|=\sup _{\theta \in E} Z_{j}(t+\theta)$, from (4.12) and (4.13), we can get

$$
Z_{i}(t)=\beta \xi_{i}\left[\sum_{j=1}^{n}\left|y_{j 0}\right|+\varepsilon\right] e^{-\alpha t}>\sum_{j=1}^{n}\left|y_{j 0}\right|+\varepsilon>\left|y_{i}(t)\right|, \quad \forall t \in E .
$$

We claim that

$$
\left|y_{i}(t)\right|<Z_{i}(t), \quad \forall t>0, i=1,2, \ldots, n
$$

Suppose that it is not true, then there exits some $i \in\{1,2, \ldots, n\}$ and $t_{i}>0$ such that

$$
\left|y_{i}\left(t_{i}\right)\right|=Z_{i}\left(t_{i}\right), \quad\left|y_{j}(t)\right| \leq Z_{j}(t), \forall t<t_{i}, j=1,2, \ldots, n \text {. }
$$

Thus

$$
\begin{aligned}
0 & \leq D^{-}\left(\left|y_{i}\left(t_{i}\right)\right|-Z_{i}\left(t_{i}\right)\right) \\
& =\limsup _{h \rightarrow 0^{-}} \frac{\left[\left|y_{i}\left(t_{i}+h\right)\right|-Z_{i}\left(t_{i}+h\right)\right]-\left[\left|y_{i}\left(t_{i}\right)\right|-Z_{i}\left(t_{i}\right)\right]}{h} \\
& \leq \limsup _{h \rightarrow 0^{-}} \frac{\left|y_{i}\left(t_{i}+h\right)\right|-\left|y_{i}\left(t_{i}\right)\right|}{h}-\liminf _{h \rightarrow 0^{-}} \frac{Z_{i}\left(t_{i}+h\right)-Z_{i}\left(t_{i}\right)}{h} \\
& \leq D^{-}\left|y_{i}\left(t_{i}\right)\right|-D_{-} Z_{i}\left(t_{i}\right) .
\end{aligned}
$$

It follows from (4.8), (4.15), and (4.18) that

$$
\begin{aligned}
D^{-}\left|y_{i}\left(t_{i}\right)\right| & \leq-\left(L_{i}^{a b}-L_{i}^{a} \Delta_{i}\right)\left|y_{i}\left(t_{i}\right)\right|+\left(\bar{a}_{i}+L_{i}^{a} \delta\right) \sum_{j=1}^{n} c_{i j}\left|y_{j t_{i}}\right| \\
& \leq-\left(L_{i}^{a b}-L_{i}^{a} \Delta_{i}\right)\left|Z_{i}\left(t_{i}\right)\right|+\left(\bar{a}_{i}+L_{i}^{a} \delta\right) \sum_{j=1}^{n} c_{i j}\left|Z_{j t_{i}}\right|<D_{-} Z_{i}\left(t_{i}\right),
\end{aligned}
$$

which contradicts to (4.19), thus (4.17) holds. Set $\varepsilon \rightarrow 0^{+}$and $M=n \max _{1 \leq i \leq n}\left\{\beta \xi_{i}+1\right\}>1$, from (4.17), we have

$$
\left|x_{i}(t)-\tilde{x}_{i}(t)\right|=\left|y_{i}(t)\right| \leq \beta \xi_{i} \sum_{j=1}^{n}\left|y_{j 0}\right| e^{-\alpha t} \leq \beta \xi_{i} n\|\phi-\tilde{\phi}\| e^{-\alpha t} \leq M\|\phi-\tilde{\phi}\| e^{-\alpha t},
$$

where $i=1,2, \ldots, n$. This completes the proof of Theorem 4.1 . 


\section{Conclusion}

In this paper, a class of generalized neural networks with arbitrary delays have been studied. Some sufficient conditions for the existence and exponential stability of the periodic solutions have been established. These obtained results are new and they improve and complement previously known results.

\section{Acknowledgment}

This work is supported by the National Natural Sciences Foundation of China under Grant 10971183.

\section{References}

[1] F. Ren and J. Cao, "Periodic solutions for a class of higher-order Cohen-Grossberg type neural networks with delays," Computers \& Mathematics with Applications, vol. 54, no. 6, pp. 826-839, 2007.

[2] F. Zhang, B. Liu, and L. Huang, "Existence and exponential stability of periodic solutions for a class of Cohen-Grossberg neural networks with bounded and unbounded delays," Computers E Mathematics with Applications, vol. 53, no. 9, pp. 1325-1338, 2007.

[3] B. Liu and L. Huang, "Existence and exponential stability of periodic solutions for a class of CohenGrossberg neural networks with time-varying delays," Chaos, Solitons E Fractals, vol. 32, no. 2, pp. 617-627, 2007.

[4] H. Hong and M. Li, Dynamics in Celler Neural Network, Academic Press, Beijing, China, 2007.

[5] M. A. Cohen and S. Grossberg, "Absolute stability of global pattern formation and parallel memory storage by competitive neural networks," IEEE Transactions on Systems, Man, and Cybernetics, vol. 13, no. 5, pp. 815-826, 1983.

[6] K. Gopalsamy and X. Z. He, "Delay-independent stability in bidirection associative memory networks," IEEE Transactions on Neural Networks, vol. 5, pp. 998-1002, 1994.

[7] T. Chen and L. Rong, "Delay-independent stability analysis of Cohen-Grossberg neural networks," Physics Letters A, vol. 317, no. 5-6, pp. 436-449, 2003.

[8] Y. Li, "Existence and stability of periodic solutions for Cohen-Grossberg neural networks with multiple delays," Chaos, Solitons \& Fractals, vol. 20, no. 3, pp. 459-466, 2004.

[9] X. Liao, C. Li, and K.-W. Wong, "Criteria for exponential stability of Cohen-Grossberg neural networks," Neural Networks, vol. 17, no. 10, pp. 1401-1414, 2004.

[10] Z. Yuan, L. Huang, D. Hu, and G. Dong, "Existence and global exponential stability of periodic solution for Cohen-Grossberg neural networks with delays," Nonlinear Analysis: Real World Applications, vol. 7, no. 4, pp. 572-590, 2006.

[11] L. Wang, "Stability of Cohen-Grossberg neural networks with distributed delays," Applied Mathematics and Computation, vol. 160, no. 1, pp. 93-110, 2005.

[12] Y. Li and X. Fan, "Existence and globally exponential stability of almost periodic solution for CohenGrossberg BAM neural networks with variable coefficients," Applied Mathematical Modelling, vol. 33, no. 4, pp. 2114-2120, 2009.

[13] C. Li and S. Yang, "Existence and attractivity of periodic solutions to non-autonomous CohenGrossberg neural networks with time delays," Chaos, Solitons E Fractals, vol. 41, no. 3, pp. 1235-1244, 2009.

[14] Z. Yuan and L. Yuan, "Existence and global convergence of periodic solution of delayed neural networks," Mathematical and Computer Modelling, vol. 48, no. 1-2, pp. 101-113, 2008.

[15] X. H. Tang and X. Zou, "The existence and global exponential stability of a periodic solution of a class of delay differential equations," Nonlinearity, vol. 22, no. 10, pp. 2423-2442, 2009.

[16] J. P. LaSalle, The Stability of Dynamical Systems, SIAM, Philadelphia, Pa, USA, 1976.

[17] A. Berman and R. J. Plemmons, Nonnegative Matrices in the Mathematical Sciences, Computer Science and Applied Mathematic, Academic Press, New York, NY, USA, 1979. 


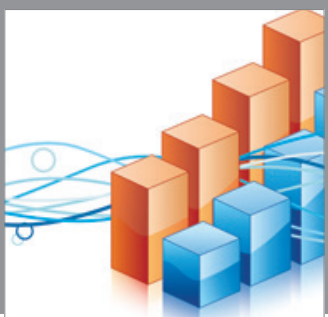

Advances in

Operations Research

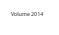

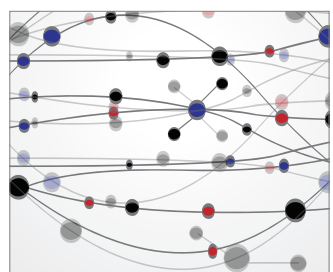

\section{The Scientific} World Journal
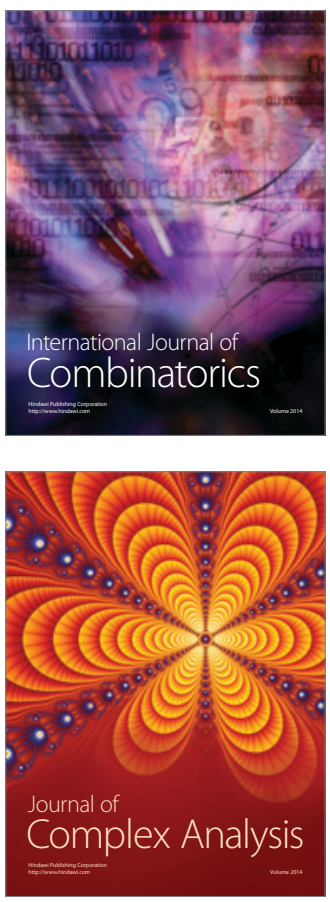

International Journal of

Mathematics and

Mathematical

Sciences
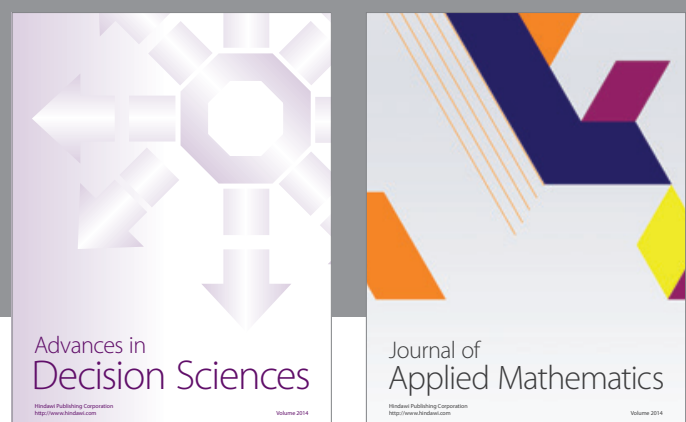

Journal of

Applied Mathematics
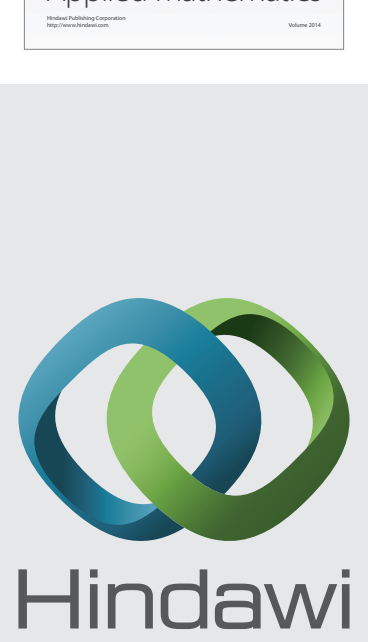

Submit your manuscripts at http://www.hindawi.com
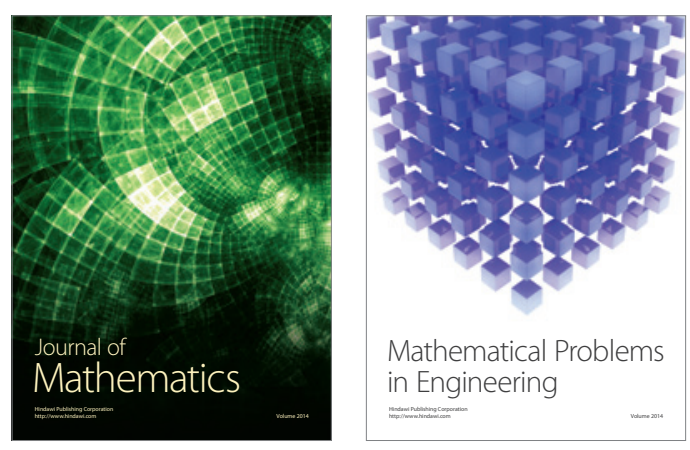

Mathematical Problems in Engineering
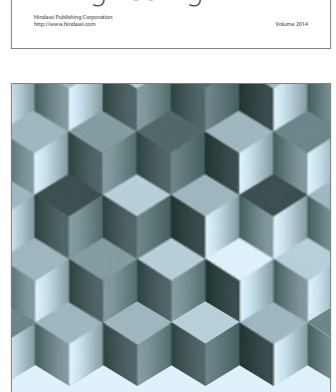

Journal of

Function Spaces
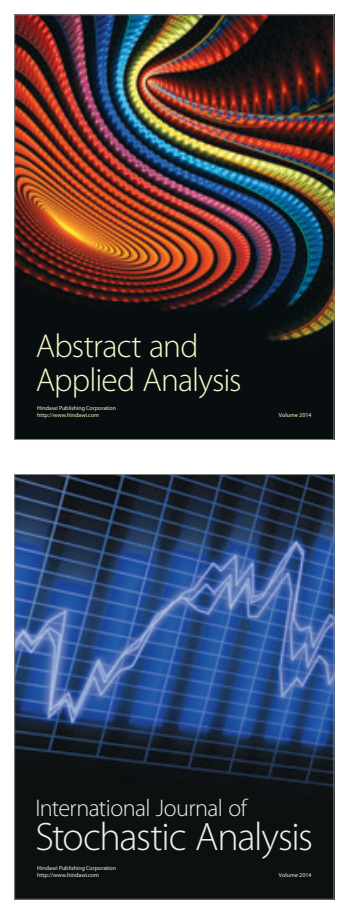

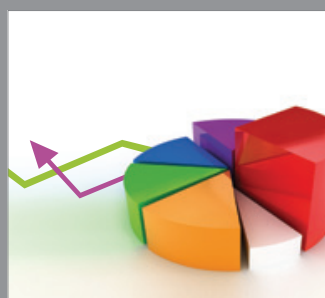

ournal of

Probability and Statistics

Promensencen
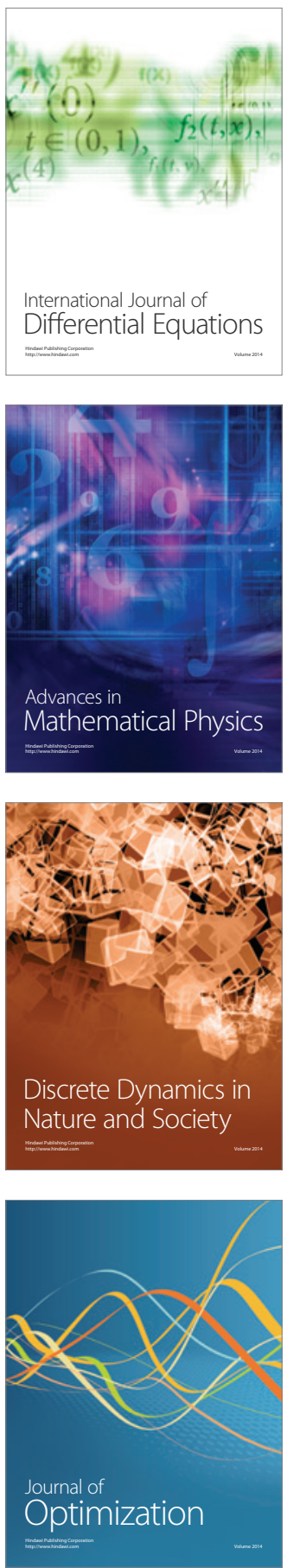